\title{
Adverbios temporales como conectores con valor consecutivo en griego antiguo ${ }^{1}$
}

\author{
José Miguel JimÉnez Delgado \\ Universidad de Sevilla \\ jmjimdelg@us.es
}

Recibido: 9-5-2012

Aceptado: 20-12-2012

\section{SUMARIO}

I. Introducción. II. Estado de la cuestión. III. Adverbios temporales griegos que funcionan como conectores consecutivos: datos y análisis. IV. De lo temporal a lo consecutivo. V. A modo de conclusión. VI. Bibliografía.

\section{RESUMEN}

El presente trabajo tiene como objetivo identificar los adverbios temporales que se utilizan como conectores con valor consecutivo en griego antiguo y determinar las características que definen el empleo de cada uno de esos adverbios como tales conectores. El corpus utilizado han sido los textos de Heródoto, Tucídides, Jenofonte y Polibio. De los datos se puede extraer como conclusión que los adverbios temporales que en griego se emplean como conectores con valor consecutivo son aquellos que expresan secuencialidad y que el camino hacia su conversión en conjunciones ilativas por parte de alguno de ellos está en su comienzo.

Palabras clave: adverbios temporales, conectores consecutivos, adverbios conjuntivos, marcadores del discurso.

\begin{abstract}
The aim of this paper is to identify the temporal adverbs that are used as connectives with consecutive nuance in Ancient Greek and to ascertain their peculiarities in that use. The searched corpus are the works by Herodotus, Thucydides, Xenophon and Polybius. We can conclude from our data that the temporal adverbs used as connectives with consecutive nuance in Ancient Greek are those expressing sequentiality and that the evolution of some of them into illative conjunctions is at its beginning.
\end{abstract}

Keywords: temporal adverbs, inferential connectors, conjunctive adverbs, discourse markers.

${ }^{1}$ Quisiera hacer constar mi agradecimiento a Emilia Ruiz Yamuza, Rafael Martínez Vázquez y Rodrigo Verano Liaño por sus sugerencias y comentarios sobre una versión previa de este trabajo, así como a los dos revisores anónimos. De los errores que restan el único responsable es el autor. 


\section{INTRODUCCIÓN}

El presente trabajo es fruto de una investigación realizada en el marco de un proyecto que tiene por objeto de estudio los adverbios conjuntivos en griego antiguo ${ }^{2}$. Los adverbios conjuntivos son aquellos que se emplean, según la denominación de Gili Gaya (1943: $\S \S 250-253)$, como enlaces extraoracionales. En griego antiguo es característico enlazar unos periodos con otros mediante conjunciones y partículas conectivas, pero también se emplean a tal efecto adverbios de distinto tipo. En este trabajo me voy a centrar en un uso conjuntivo de los adverbios temporales: su empleo para poner en relación dos miembros discursivos independientes entre los que hay una relación de tipo consecutivo.

El uso de adverbios temporales para presentar al miembro del discurso en el que se encuentran como una consecuencia de un miembro anterior es prototípico de los denominados por Martín-Portolés (1999: 4099) «conectores consecutivos». En español encontramos adverbios temporales como entonces o luego, que han terminado evolucionando a una conjunción ilativa. En griego encontramos ejemplos similares, algunos de ellos tan claros como el siguiente:

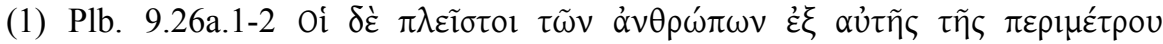

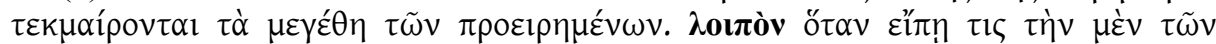

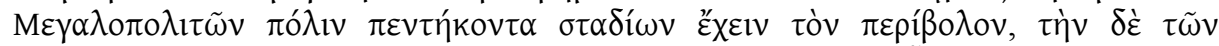

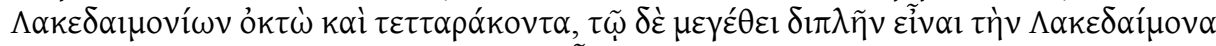

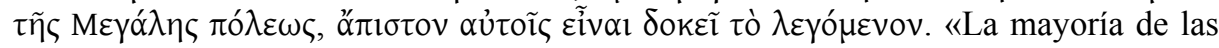
personas dan fe de la magnitud de las ciudades mencionadas a partir de su perímetro. Luego cuando alguien dice que la ciudad de Megalópolis tiene un contorno de cincuenta estadios y la de Esparta cuarenta y ocho, pero que Esparta dobla en magnitud a Megalópolis, les parece que lo que dice no es creíble.»

El ejemplo constituye una verdad de carácter general articulada en dos partes conectadas con $\lambda$ oiróv. Véase que la segunda parte (si nos dicen que una ciudad con perímetro mayor que otra es, sin embargo, de menor tamaño, nos provoca extrañeza) es consecuencia de la primera (los hombres calculamos el tamaño de las ciudades por su perímetro). Por lo demás, el adverbio se utiliza en primera posición de frase, esto es, entre los dos miembros discursivos a los que pone en relación, una posición muy armónica con la función conjuntiva. Véase que el adverbio no añade ninguna modificación de carácter temporal ni al predicado ni a la oración, simplemente articula la relación consecutiva entre esos dos miembros ${ }^{3}$.

En lo que sigue, voy a determinar cuáles son los adverbios temporales que en griego presentan usos que se pueden calificar de consecutivos y cuáles son las condiciones que permiten hacer una lectura de ese tipo. Los ejemplos no suelen ser tan claros como (1), pero constituyen un verdadero problema filológico en el momento en que las

2 FFI 2009-13908-C03-03: «Los adverbios conjuntivos en Heródoto y en la prosa helenística: un capítulo desatendido de la gramática griega».

${ }^{3}$ Las características de los adverbios conjuntivos se pueden consultar en Crespo (2011), MartínezRuiz (2011), Martín-Portolés (1999), Llamas (2010), Quirk et alii (1985: 631-646). 
traducciones vacilan con frecuencia entre el carácter temporal del adverbio y el matiz consecutivo del contexto, matiz que también recogen los léxicos. En este sentido, no está de más advertir que las traducciones son propias y tienen un carácter meramente instrumental, de forma que tratan de ser tan próximas al original como sea posible. Como corpus para el estudio he utilizado los textos de cuatro historiadores griegos señeros cuyas obras van desde la época clásica a la helenística: Heródoto, Tucídides, Jenofonte y Polibio. En principio, el corpus tiene una limitación digna de ser tenida en cuenta a la hora de estudiar el funcionamiento discursivo de determinados adverbios: los textos de estos autores tienen un carácter fundamentalmente narrativo, aunque también incluyen segmentos de tipo explicativo-expositivo, descriptivo y algunas secuencias argumentativas en estilo directo o indirecto. No obstante, en algunas obras de Jenofonte sí que abundan las secuencias argumentativas de tipo dialógico ${ }^{4}$.

\section{ESTADO DE LA CUESTIÓN}

Como ya hemos apuntado, el empleo de adverbios temporales como conectores consecutivos es propio de toda clase de lenguas. Han recibido especial atención en la bibliografía el adverbio entonces del español (Pons 1998: 148-166, Martín-Portolés 1999: 4107) y el adverbio then del inglés (Schiffrin 1987: 246-266). En ambos casos nos encontramos con adverbios que suelen emplearse con sentido anafórico para cohesionar narraciones desde un punto de vista temporal (Fuentes 2009: s. u.

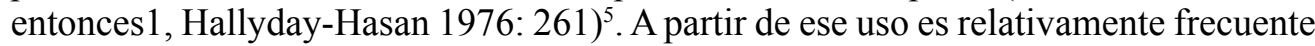
que desarrollen significados de tipo consecutivo cuando entre los dos eventos que conectan hay una relación de este tipo (König-Traugot 1988: 111-113, Pons 1998: 162-166). En la bibliografía se insiste en su carácter fronterizo, en el sentido de que siempre queda parte de su significado temporal más primario, no solo porque se siguen usando como tales adverbios temporales en sincronía, sino porque también se puede rastrear su valor temporal en buena parte de los casos en que conectan una oración que es consecuencia de la anterior. Así, Martín-Portolés (1999: 4107) califican de «débil» el sentido consecutivo de entonces y Schiffrin (1987: 246) insiste, por ejemplo, en que cuando se emplea then en un periodo condicional no deja de sentirse la relación temporal entre prótasis y apódosis, esto es, que si la condicional es hipotética y el cumplimiento de la apódosis depende del de la prótasis, no se puede negar cierta secuencialidad temporal en el hecho de que el cumplimiento de esta última suele ser anterior 6 .

Los valores consecutivos de ciertos adverbios temporales griegos tampoco han pasado inadvertidos. Es el caso de 入oıróv, cuya evolución semántica desde época clásica ha sido estudiada por Cavallin (1941), que llega a la conclusión de que estos usos, a

${ }^{4}$ La correlación de los tipos textuales con los tipos de adverbios conjuntivos empleados se estudia en Domínguez (2010) y Martínez (2011).

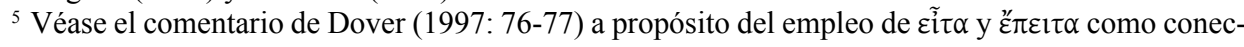
tores.

${ }^{6}$ Schiffrin recoge la opinión de que el contenido semántico de iflthen es el de la conexión lógica representada con $\rightarrow$ (n. 9 del capítulo VIII). 
los que denomina «lógicos» ${ }^{7}$, son poco frecuentes y difíciles de separar de los propiamente temporales (pp. 133-136), pero que, en todo caso, derivan de su empleo como adverbio temporal de posterioridad ${ }^{8}$. Aparte del trabajo de Cavallin, el interés por el funcionamiento de los adverbios temporales griegos como conectores consecutivos es reciente (Conti en prensa, Jiménez en prensa, Maquieira 2012). No obstante, ha llama-

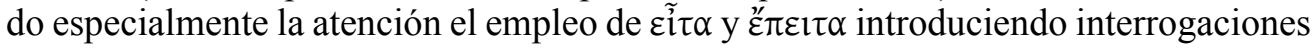
enfáticas, que se suele considerar como un uso de tipo consecutivo, cf. Rehdantz-Blass (1909: 65) y Sicking-Van Ophuijsen (1993: 17-18). En el caso de ع̌ $v \theta \alpha$ y $\varepsilon v \tau \alpha \tilde{v} \theta \alpha$, dos adverbios locales que se emplean frecuentemente con sentido temporal, resulta llamativo que Denniston (1950: 236) ponga en relación el sentido ilativo que la partícula $\delta$ ń desarrolla en el s. IV a. C. con la frecuencia con la que esta se construye reforzando a

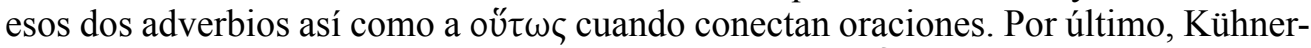
Gerth (1904: 122) identifican un sentido consecutivo de en los que observan que de un sentido de posterioridad anafórico (zeitliches nunmehr) se desarrolla un sentido inferencial (folgerndes nunmehr, d. i. wie sich nunmehr (aus dem Gesagten) ergibt).

\section{ADVERBIOS TEMPORALES GRIEGOS QUE FUNCIONAN COMO CONECTORES CONSECUTIVOS: DATOS Y ANÁLISIS}

Si hacemos un rastreo de las acepciones recogidas en los léxicos de los adverbios temporales griegos podemos determinar que, en principio, presentan valores consecu-

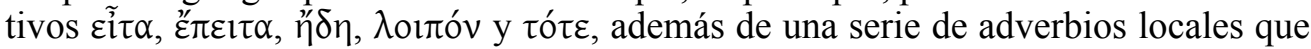
poseen significados temporales tanto o más frecuentes que los locales, en concreto, $\tilde{\varepsilon} v \theta \alpha, \dot{\varepsilon} \nu \tau \alpha \tilde{u} \theta \alpha$ y $\dot{\varepsilon} \vee \tau \varepsilon \tilde{v} \theta \varepsilon v$, probablemente también $\tilde{\varepsilon} v \theta \varepsilon v$ (cf. infra). Hay además un ejemplo herodoteo en el que es posible una lectura consecutiva de la preposición $\mu \varepsilon \tau$ ́́ usada como adverbio.

Desde un punto de vista discursivo, es característico de los adverbios temporales y expresiones equivalentes que se utilicen para cohesionar los eventos que constituyen una narración desde un punto de vista cronológico (Martínez en prensa, Hallyday-Hasan 1976: 261-267, Quirk et alii 1985: 1451). Dentro de su empleo como elementos de cohesión discursiva está la función de conectar unos eventos con otros. Se trata de una función propia de los denominados «conectores temporales» por Fuentes (2009: 378) o «temporal discourse markers» por Fraser (2006: 197) ${ }^{9}$. En este sentido, los adverbios que nos ocupan se caracterizan por usarse para poner en relación unos periodos con otros, pero sin referirse a un segmento concreto de la línea temporal, sino más bien a la secuencialidad característica de esta. Antes de entrar en los usos propiamente conse-

${ }^{7}$ «Es handelt sich um das LOGISCHE $\lambda$ ouróv, das vermittels kausaler Bande das Glied, in welchem steht, mit einem vorhergehenden Glied vereinigt» (p. 134).

${ }^{8}$ Véase también Blomqvist (1969: 100-103) y Loudová (2009: 304-305), que hablan de «inferen-

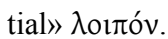

${ }^{9}$ Martínez (2012) propone distinguir, sobre una base fundamentalmente etimológica, una subclase de marcadores discursivos a los que denomina «ordenadores temporales», que se usan como marca de la progresión temática del discurso. 
cutivos, merece la pena detenerse en algunos ejemplos de su función como conectores puramente temporales, ya que es esta la que da pie a la interpretación consecutiva de estos adverbios en los contextos adecuados:

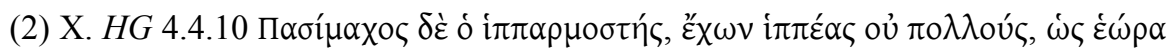

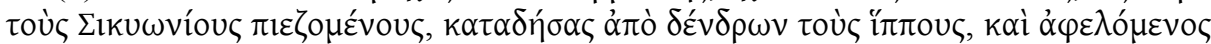

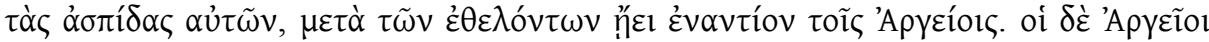

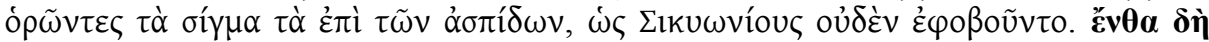

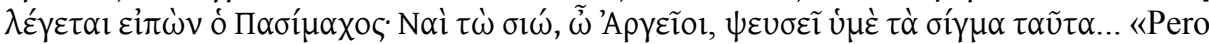
Pasímaco, comandante de caballería (espartano), con unos pocos jinetes, cuando vio que los sicionios estaban en problemas, ató sus caballos a los árboles, cogió sus escudos y con voluntarios se dirigió contra los argivos. Pero los argivos, al ver las sigmas en los escudos, no temieron nada pensando que eran sicionios. Entonces fue cuando se cuenta que dijo Pasímaco: "Por los dos dioses, argivos, os van a engañar estas sigmas"...»

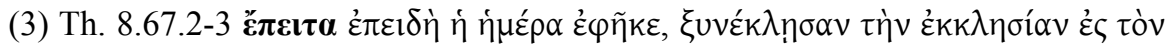

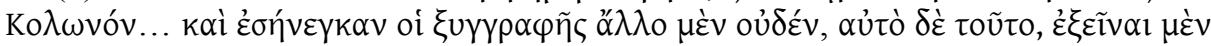
'A

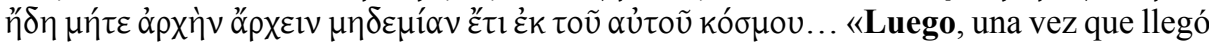
el día, encerraron a la asamblea en Colono... Y los comisionados no introdujeron más que la posibilidad de que los atenienses expresaran su opinión con impunidad si alguno quería hacerlo... Entonces fue cuando se dijo ya con claridad que el poder del gobierno existente quedaba sin efecto...»

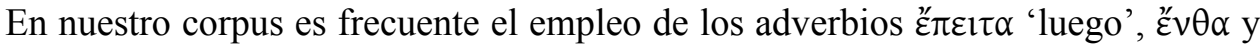
$\varepsilon ่ V \tau \alpha \tilde{\theta} \theta \alpha$ 'entonces' en primera posición con la función de conectar los eventos que constituyen la narración en su sucesión cronológica. "Ev $\theta \alpha$ y $\varepsilon \dot{v} \tau \alpha \tilde{v} \theta \alpha$ se suelen construir además con la partícula $\delta$ ń para introducir un segmento discursivo que sigue a lo anterior, pero que supone un punto de inflexión ${ }^{10}$. Además de con la partícula $\delta \eta ́$, cuando estos adverbios se usan como conectores se suelen combinar con conjunciones del tipo de $\delta \varepsilon ́$ y koú, pero también tienen capacidad para introducir por sí solos su miembro discursivo. Véanse los siguientes ejemplos:

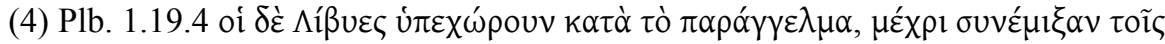

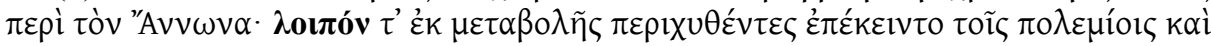

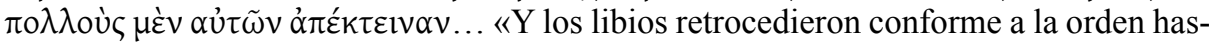
ta que se encontraron con los de Hanón. Y luego, tras realizar una maniobra envolvente, atacaron a los enemigos y mataron a muchos de ellos...»

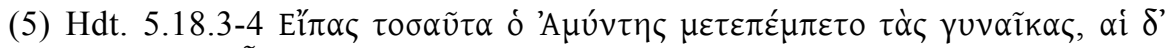

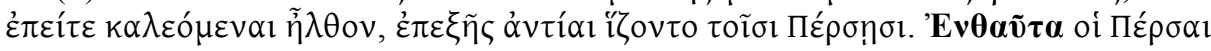

${ }^{10}$ Classen interpreta $\varepsilon^{\prime} \nu \tau \alpha \tilde{v} \theta \alpha \delta$ $\delta$ en 8.67 .3 como «erst auf dieser Grundlage». También es interesante

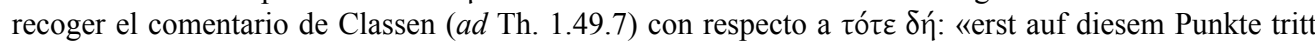

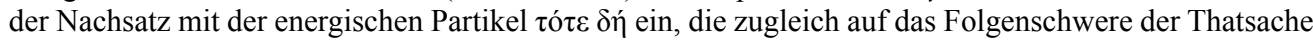
hinweist». 


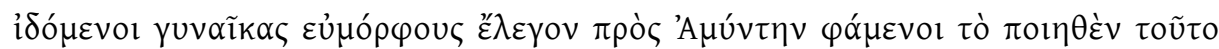

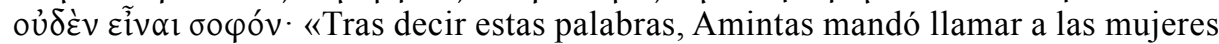
y estas, tras acudir a la llamada, se sentaron por orden frente a los persas. Entonces los persas, al ver bellas mujeres, dijeron a Amintas que lo que había hecho no era inteligente».

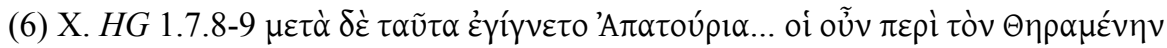

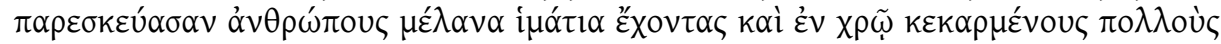

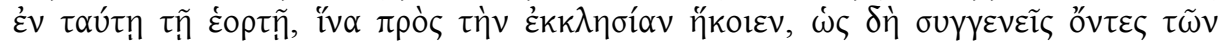

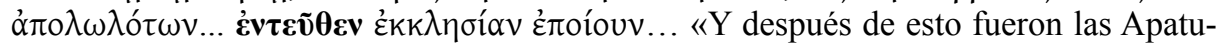
rias...Así pues, los partidarios de Terámenes prepararon a muchos con ropas negras y rapados en esta fiesta para que fueran a la asamblea como si fueran familiares de los fallecidos. Entonces hicieron una asamblea...»

Estos adverbios tienen distintos significados, pero todos compatibles con la secuencialidad o progresión cronológica. Además, comparten una capacidad relacional

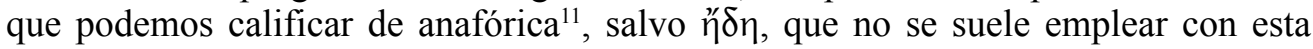
función de cohesión temporal, si bien hay algunos ejemplos en que hace referencia a una fase temporal previa que coincide con el evento anterior:

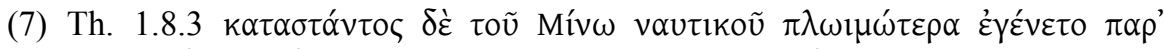

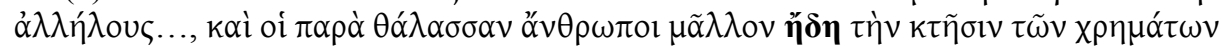

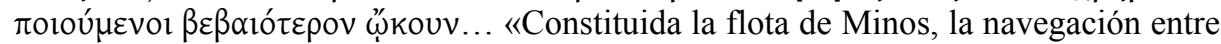
ellos fue más accesible... y los habitantes de las regiones costeras empezaron ya a hacer más fortuna y a vivir de forma más estable...»

Los valores de tipo consecutivo derivan directamente del empleo de estos adverbios como conectores temporales. Con dicha función discursiva, estos adverbios tienden a colocarse en primera posición de frase para articular la relación de los dos miembros discursivos entre los que se colocan. En esta posición el adverbio tiene alcance sobre toda su oración y no es un simple adjunto del verbo. Su sentido tiene que ver, fundamentalmente, con la progresión en la línea del tiempo de los eventos que conectan.

Si pasamos al estudio de su empleo como conectores con valor consecutivo entre oraciones independientes ${ }^{12}$, los ejemplos presentan características de distribución y comportamiento relativamente dispares. Voy a hacer un recorrido por esas características empezando por los adverbios que presentan los ejemplos más claros:

${ }^{11}$ «[...] as an anaphor, then marks the temporal relation between two linguistic events, thus displaying temporal connections between events internal to the discourse.» (Schiffrin 1987: 246).

${ }^{12}$ En este trabajo no tengo en cuenta los ejemplos en los que los adverbios en cuestión se emplean entre una oración subordinada y su principal, aunque también desarrollen sentidos consecutivos, $\mathrm{cf}$. X.

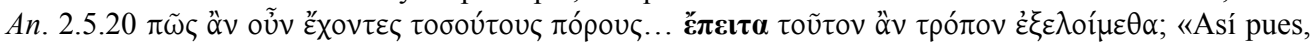
¿cómo, si tenemos tantas posibilidades, elegiríamos entonces esta manera?». Para este empleo, denominado «apodótico», véase Ruiz (2011). 


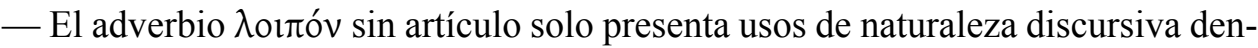

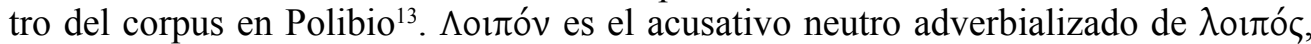

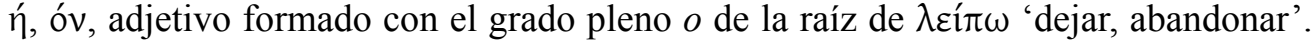
Como explica Cavallin (1941), este adjetivo se usa con sentido temporal desde Píndaro ${ }^{14}$ para hacer referencia al tiempo que resta y, por extensión, al futuro. Una traducción aproximada al español sería 'de ahora en adelante', expresión adverbial de carácter delimitativo ${ }^{15}$ que implica que un evento tiene lugar a partir de un punto concreto de la línea del tiempo. Polibio usa $\lambda$ oıróv como conector entre los dos miembros de una relación de tipo consecutivo con bastante frecuencia ${ }^{16}$, siempre en primera posición y sin ninguna conjunción o partícula que refuerce la conexión con lo anterior. Se trata de una evolución del adverbio bastante curiosa, pero lo más importante es que los usos discursivos de $\lambda$ oı óv se generalizan en época postclásica y perviven en griego moderno ${ }^{17}$. En nuestro corpus encontramos ejemplos en distintos contextos. Así, el adverbio se puede emplear en secuencias narrativas donde entre los dos sucesos que articula se establece una relación de tipo consecutivo:

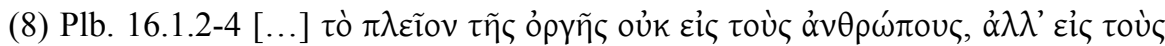

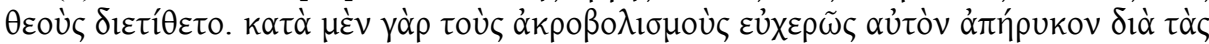

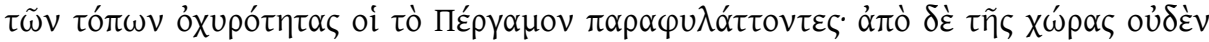

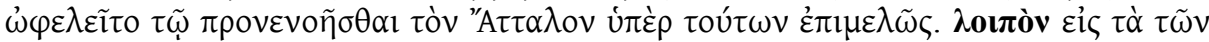

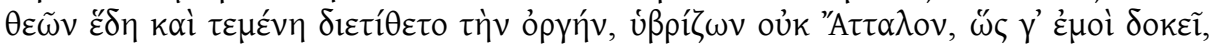
$\pi \circ \lambda \dot{v} \delta \dot{\varepsilon} \mu \tilde{\alpha} \lambda \lambda$ ov $\dot{\varepsilon} \alpha u \tau o ́ v$. «La mayor parte de su ira no la volcó con los hombres, sino con los dioses, pues en las escaramuzas la guarnición de Pérgamo lo mantuvo a distancia con facilidad por la firmeza de la fortificación y del territorio no obtuvo provecho al haberse preocupado Átalo de evitarlo. Luego dirigió su ira contra las sedes y los terrenos de los dioses, violentando no a Átalo, según me parece a mí, sino más bien a sí mismo.»

El pasaje pertenece al comienzo del libro $16 \mathrm{y}$, en concreto, a las operaciones de Filipo V en Pérgamo. El saqueo de los templos y propiedades religiosas se produjo después de que hubiera saqueado el territorio, pero, al mismo tiempo, la causa de que

${ }^{13}$ Cavallin recoge un ejemplo jenofonteo donde interpreta $\tau$ tò $\lambda$ ol $\pi$ óv como conector puramente tem-

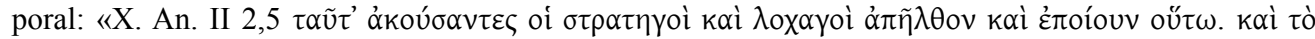

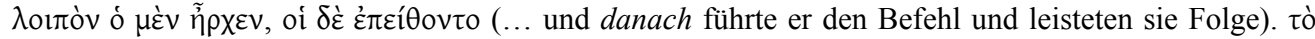

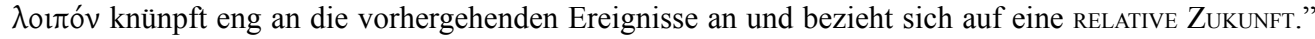
(p. 122).

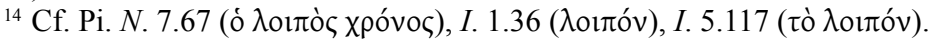

${ }^{15}$ García Fernández (1999: 3135).

${ }^{16}$ Los ejemplos más claros, en mi opinión, son los siguientes: 1.15.11, 4.32.5, 5.30.5, 5.63.1, 6.38.4, 6.41.10, 8.11.2, 9.15.10, 9.18.3, 9.26a.2, 9.31.6, 10.5.7, 10.16.8, 10.20.6, 10.45.2, 11.5.4, 12.4.3, 12.25g.2, 12.25h.2, 12.26c.1, 16.1.4, 18.18.13, 29.9.5, 30.9.17, 32.10.8, 33.1.8, 38.16.2, 38.16.11. Mauersberger et alii (s. u. C.2) recogen treinta y ocho casos con el significado de «folgerndes (wie) unter diesen Umständen, auf diese Weise, so; folglich, also, daher, infolgedessen».

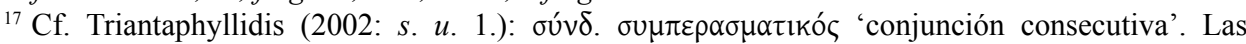
gramáticas lo incluyen dentro de la nómina de conjunciones ilativas, equivaliendo a esp. luego, cf.

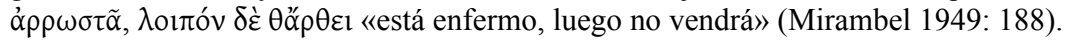


se dirigiera contra los dioses fue que no sacó gran cosa de las propiedades profanas, ya que Átalo había tomado medidas contra un previsible saqueo por parte de Filipo. En

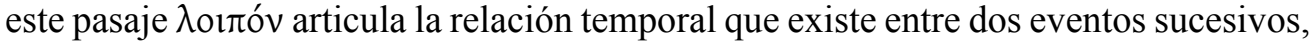
pero también el carácter consecutivo que esta tiene. Para entender ese carácter hay que

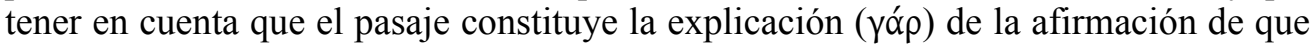
Filipo cargó su ira contra los dioses a partir del hecho de que no había podido obtener nada de los hombres.

También se emplea en otros contextos donde la coordenada temporal está desactualizada, por ejemplo, en descripciones y en razonamientos generales ${ }^{18}$ :

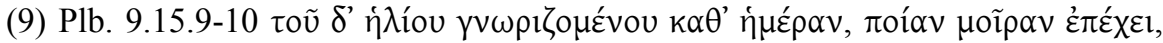

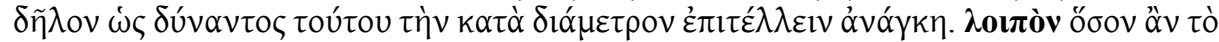

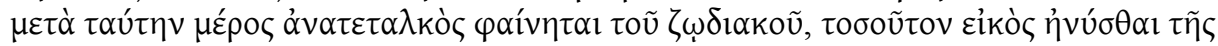

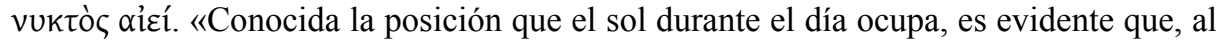
ponerse, tiene que levantarse la parte diametralmente opuesta. Luego cuanto aparezca levantada la parte del Zodíaco que sigue, tanto es lógico que se haya cumplido de la noche siempre.»

Este fragmento es parte de la descripción de los conocimientos que un general debe tener para calcular el tiempo. El cálculo de las horas del día es sencillo, pero para calcular las de la noche hay que tener ciertos conocimientos astronómicos, ya que se calculan a partir de la posición en el Zodíaco que ocupa el sol durante el día. Esta descripción es abstracta en el sentido de que puede actualizarse siempre que sea necesario, pero, además, el pasaje citado no tiene una estructura temporal interna, las operaciones articuladas con $\lambda$ oıtóv no se suceden en el tiempo, sino que la primera es una premisa que explica la segunda.

Incluso he encontrado un ejemplo en el que el adverbio introduce, aunque a cierta distancia, una interrogación enfática, lo propio de عĩ $\alpha$ y ع̌ tinuación. El ejemplo está en relación con el hecho de que Polibio no emplea esos dos adverbios como conectores con valor consecutivo:

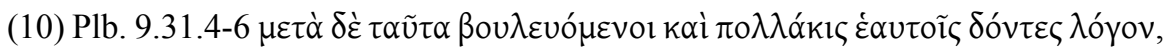

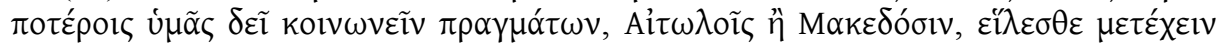

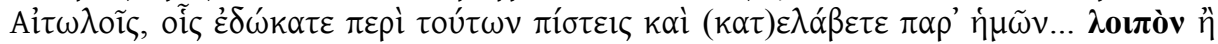

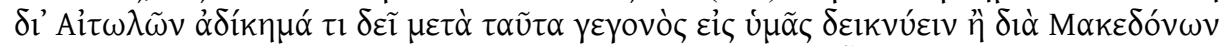

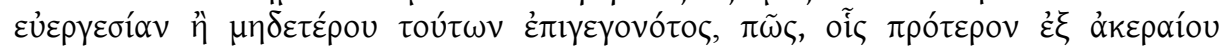

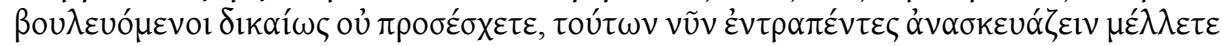

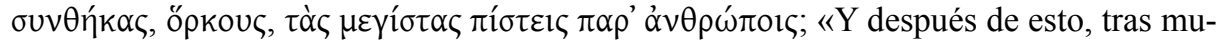
chas deliberaciones y discusiones entre vosotros mismos sobre la conveniencia de aliarse con etolios o macedonios, elegisteis uniros a los etolios, a los que disteis vuestros juramentos y de los que recibisteis los nuestros... Luego tenéis que demostrar que se ha producido posteriormente alguna injusticia de los etolios contra vosotros o algún favor de los macedonios, o, si no ha sucedido ninguna de estas cosas, ¿cómo ahora, por hacer

${ }^{18}$ Véase también (1). 
caso a los que antes no os adheristeis deliberando justamente y sin presiones, vais a destruir pactos, juramentos y las mayores prendas entre los hombres?»

La sintaxis del pasaje es un tanto compleja y se inserta dentro de la alocución del enviado etolio Cleneas. Cleneas afirma que los espartanos ya han sellado una alianza con los etolios, por lo que se sorprende de que ahora los espartanos quieran romper

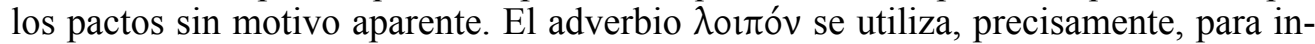
troducir el segmento discursivo que refleja su sorpresa, poniéndolo en relación con el segmento en el que aparecen los motivos de la misma.

- El adverbio عĩ $\tau \alpha$ es una forma derivada del locativo del tema demostrativo IE

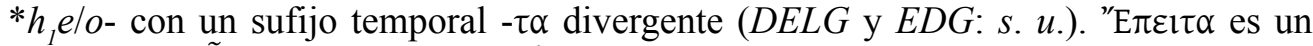
refuerzo de عĩ $\tau \alpha$ con el preverbio $\varepsilon \dot{\pi}(\mathrm{l})-$, que insiste en la posterioridad. No obstante,

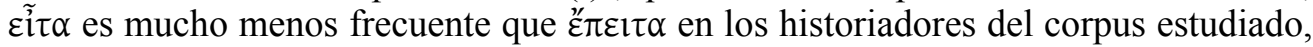
donde solo tienen valores consecutivos, hasta donde sé, en Jenofonte ${ }^{19}$. El uso de estos dos adverbios como conectores consecutivos presenta una especialización muy llamativa y que viene recogida en los léxicos ${ }^{20}$ : es muy habitual, y así lo documentan todos

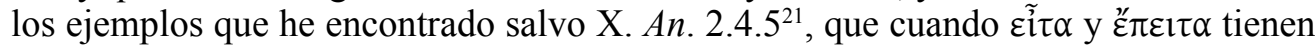
sentido consecutivo introduzcan interrogaciones enfáticas cuya respuesta se puede deducir de lo anterior ${ }^{22}$. Véanse los siguientes ejemplos:

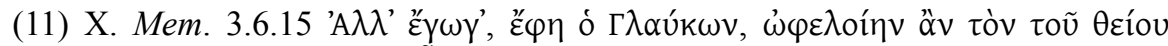

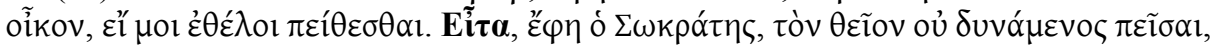

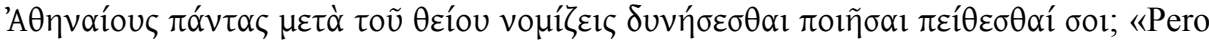
es que yo, dijo Glaucón, podría ser de utilidad para la casa de mi tío si quisiera hacerme caso. Entonces, dijo Sócrates, ¿si no puedes convencer a tu tío, crees que podrás hacer que todos los atenienses junto con tu tío te hagan caso?»

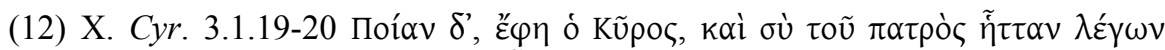

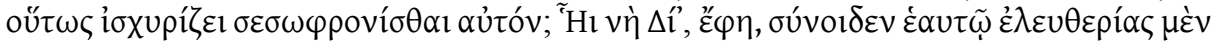

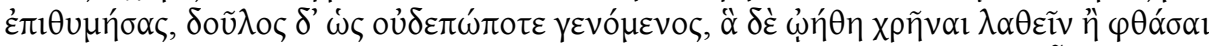

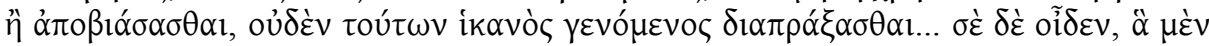

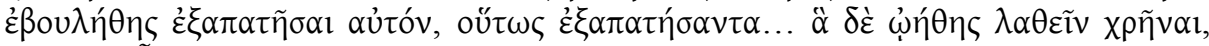

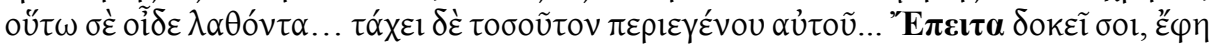

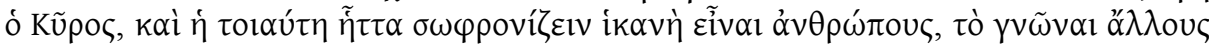

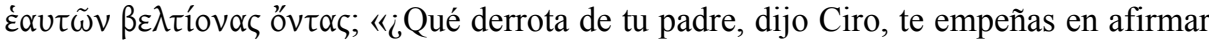
que lo ha hecho un hombre prudente? Aquella, dijo, por la que, por Zeus, tiene conciencia de que deseaba la libertad, pero se convirtió en esclavo como nunca, y que no fue

${ }^{19}$ Cf. X. An. 2.4.5, Cyr. 2.2.31, 3.1.20, 7.5.83, HG 7.3.10, Mem. 2.7.5, 2.7.7, Oec. 2.4, Smp. 4.2

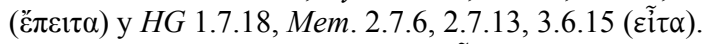

${ }^{20}$ Cf. LSJ: s. uu. y DGE: s. u. हĩ $\alpha$.

${ }^{21} D G E$ recoge un ejemplo consecutivo de عĩ $\alpha \alpha$ en el que tampoco introduce una interrogación enfática, me refiero a X. An. 1.2.25, donde el adverbio se usa como apodótico tras oración de participio.

${ }^{22} \mathrm{Cf}$. LSJ: «in questions or exclamations to express surprise, indignation, contempt, sarcasm, and the

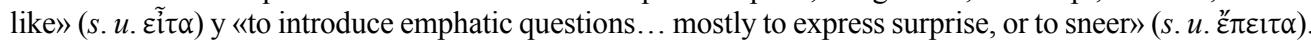


capaz de realizar ninguna de las cosas en las que creía era necesario pasar inadvertido, adelantarse o imponerse por la fuerza... Y sabe que, en lo que quisiste engañarle, así le engañaste... Y en lo que pensabas que era necesario pasar inadvertido, sabe que así lo hiciste... Y le superaste tanto en rapidez... Entonces, dijo Ciro, ¿te parece que una derrota tal es capaz de hacer prudentes a las personas, el darse cuenta de que otros son superiores a ellos mismos?»

Los ejemplos, todos ellos jenofonteos, son propios de segmentos discursivos dialógicos en los que el adverbio introduce una interrogación con la que el hablante muestra su sorpresa. En general, el adverbio conecta la interrogación con el turno de habla anterior y no dentro de un mismo turno de habla ${ }^{23}$. En este tipo de ejemplos, la secuencialidad temporal se ve relegada a un plano abstracto en el que se desactualiza: el

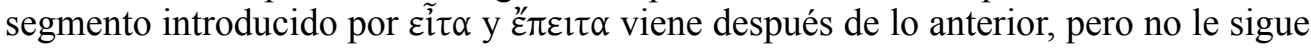
en el tiempo físico, sino en la línea abstracta de la argumentación.

Sea como fuere, el sentido consecutivo de estos dos adverbios es bastante débil y, en los términos de Martín-Portolés (1999: 4107 a propósito de entonces), la consecuencia que introducen no es paráfrasis de la causa y el conector muestra el progreso en la aportación de nuevas informaciones sobre un tópico de carácter general. Así, en el primer pasaje Glaucón, un joven que quiere convertirse en un líder político ateniense, afirma que no puede ser de utilidad a su tío porque no le escucha, de modo que Sócrates se sorprende de que pretenda convencer a toda la ciudad si no es capaz de hacer lo propio con su tío. En (12) Ciro conversa con Tigranes en el juicio del padre de este último por haber roto su pacto con Ciro. Según Tigranes, su padre ha aprendido a ser prudente al haber sido capturado por Ciro. Entonces Ciro le pregunta si realmente considera Tigranes que una derrota de ese tipo supone semejante enseñanza, pregunta cuya respuesta es evidente, pero que da pie a que Tigranes desarrolle su argumento. Por

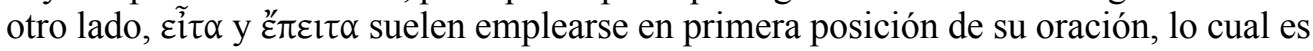
muy armónico con la función de conector. No obstante, la mayor parte de los adverbios que en griego funcionan como conectores suelen construirse con otras conjunciones y partículas que también conectan con el miembro discursivo anterior. En el caso de عĩ $\tau \alpha$

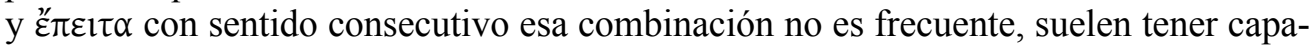
cidad para conectar por sí solos, si bien hay ejemplos en que se combinan con $k \alpha i^{24}$.

- Tó $\varepsilon$ es un adverbio que se puede usar en griego para conectar los eventos que forman parte de una narración lo mismo que el adverbio latino relacionado etimológicamente tum (Hilton 1999). Esta capacidad de conectar está ligada a su naturaleza demostrativa, no en vano se trata de un adverbio derivado del tema pronominal *to- con un sufijo temporal que hemos visto con otra forma en हĩ $\tau \alpha \mathrm{y}$

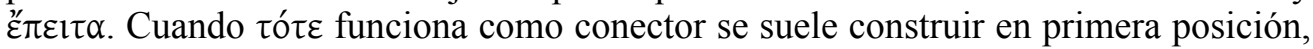

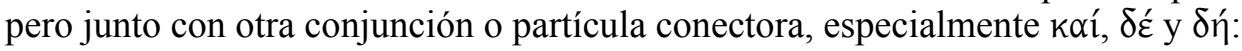

${ }^{23}$ Según Martín-Portolés (1999: 4108), con respecto a entonces: «Quien profiere la intervención con entonces no se compromete con la verdad de lo mantenido por su interlocutor, aunque extrae de su intervención una consecuencia».

${ }^{24}$ Cf. X. Cyr. 2.2.31, HG 7.3.10, Oec. 2.4, Smp. 4.2. 


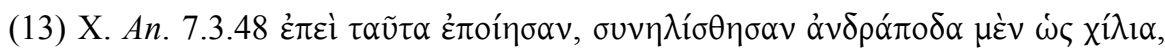

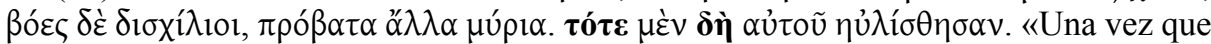
hicieron esto, concentraron unos mil esclavos, dos mil bueyes y diez mil cabezas de ganado menor. Entonces acamparon allí.»»

El uso de $\tau o ́ \tau \varepsilon$ con valor consecutivo ${ }^{25}$ está estrechamente relacionado con su uso como conector puramente temporal en ejemplos como el anterior. Este adverbio denota sucesión inmediata o también enmarque (Fuentes 2009: $s . u$. entonces1), esto es, que el evento representado en su oración se desarrolla en un marco temporal previamente definido. No obstante, su uso como conector implica secuencialidad, independientemente de que pueda darse cierto solapamiento con el evento representado en la oración anterior (Romera 2003). En general, cuando tiene valor consecutivo el adverbio suele introducir el último miembro de una secuencia narrativa, que es el efecto de lo que se ha narrado:

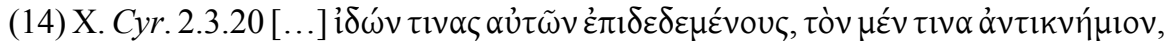

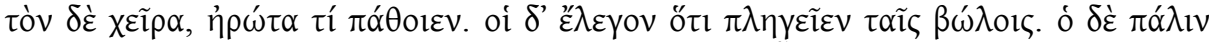

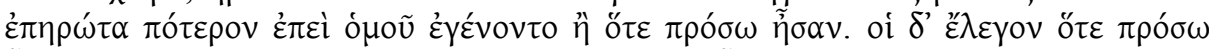

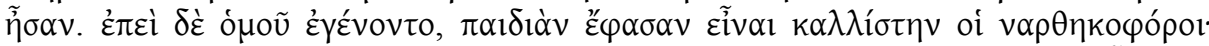

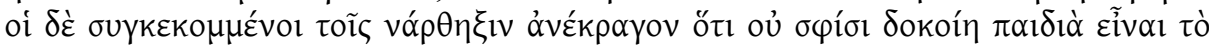

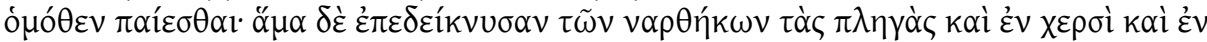

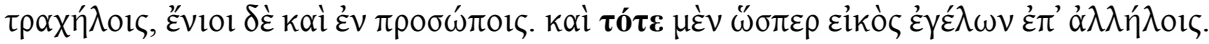
«Al ver a algunos vendados, unos en una pierna, otros en una mano, les preguntó que había pasado. Y ellos le respondieron que les habían dado con los terrones. Y les preguntó otra vez si cuando estaban juntos o cuando estaban separados. Le respondieron que cuando estaban separados y los que llevaban cañas dijeron que cuando estaban juntos fue muy divertido. Y los que habían sido golpeados con las cañas gritaron que no les parecía ninguna diversión que les pegaran de cerca y, al mismo tiempo, enseñaron los golpes de las cañas en las manos y en el cuello, algunos incluso en la cara. Y entonces, como es natural, se rieron los unos de los otros.»

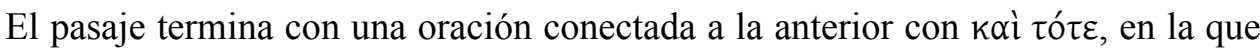
se representa una situación que sigue inmediatamente a la conversación narrada y que

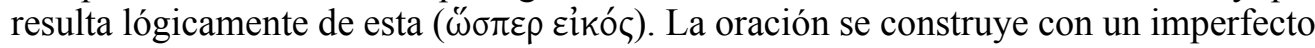
narrativo y, si en español es mejor traducirlo por un pretérito indefinido, también es cierto que este tipo de pasajes narrativos pueden cerrarse en griego tanto con un aoristo como con un imperfecto, cf. Martínez (2011: 94-95).

Un esquema más curioso es el que consiste en emplear $\tau$ ó $\tau \varepsilon$ para recuperar el hilo de la narración tras una digresión que da lugar al evento que se representa en la oración que introduce. Powell (1966: 360) denomina a este empleo «reanudativo» (= resumptive):

${ }^{25}$ Cf. Hdt. 1.84.5, 4.143.3, 6.65.3, Th. 1.133.1, X. An. 2.4.22, 7.1.33, 7.4.4, Cyr. 2.3.20, 4.1.24, Smp. 8.18, Plb. 4.35.4, 6.9.9, 6.57.8, 10.16.4, 10.18.13, 23.5.9, 38.18.12. 


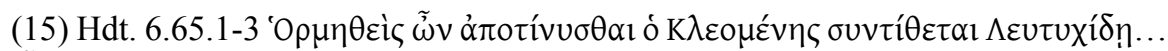

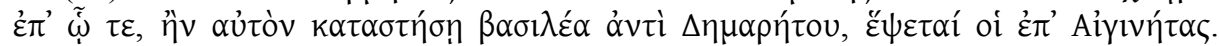

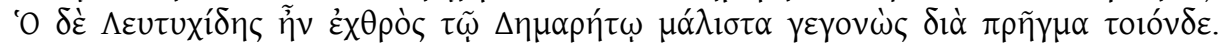

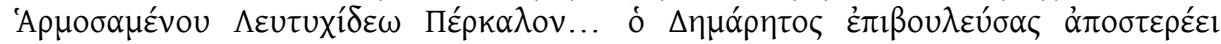

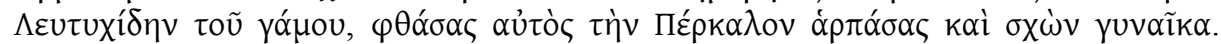

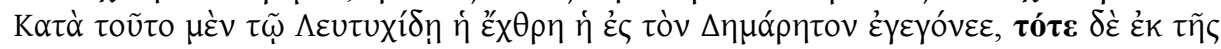

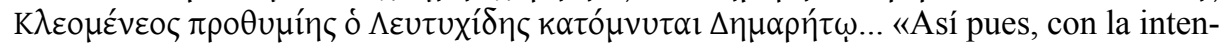
ción de vengarse Cleómenes hace un pacto con Leotíquidas... con la condición de que si lo colocaba como rey en lugar de Demárato le acompañaría contra Egina. Leotíquidas se había convertido en un enemigo acérrimo de Demárato por la causa siguiente: habiéndose comprometido Leotíquidas con Pércalo..., Demárato deja a Leotíquidas sin boda a propósito adelantándose en raptar y casarse con Pércalo. Por ello Leotíquidas tenía su enemistad con Demárato y entonces, a instancias de Cleómenes, Leotíquidas acusa solemnemente a Demárato...»

Este pasaje es el episodio en el que Heródoto narra el pacto al que llegó Cleómenes con Leotíquidas para derrocar al rey espartano Demárato. El pasaje comienza con el pacto en sí, luego viene una digresión en la que se explica que Leotíquidas accedió por la enemistad que tenía contra Demárato. Al final se hace una recapitulación de la digresión y se vuelve al hilo principal de la historia. Véase que esa última oración

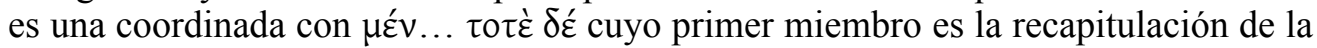
digresión y el segundo la acusación que Leotíquidas hace contra Demárato en cumplimiento del pacto y a causa de su enemistad con aquel. El adverbio ras en absoluto incompatibles: por un lado, define el matiz consecutivo de la relación de los dos miembros de la coordinación y, por otro, vuelve a la secuencia temporal de la historia. La traducción de Schrader en Gredos, un tanto redundante, hace justicia a esa doble lectura: «de ahí que, en aquellos momentos, Leotíquidas, a instancias de Cleómenes, acusara solemnemente a Demárato».

Como estamos viendo, el valor consecutivo de $\tau$ ó $\tau \varepsilon$ es muy débil y se inserta dentro de su función como conector temporal en griego. Este adverbio expresa que el evento representado en su oración es inmediatamente posterior al que precede. Por ello, cuando conecta dos miembros discursivos entre los que se establece una relación consecutiva, $\tau o ́ \tau \varepsilon$ es un nexo débil con respecto a esa relación, ya que se da cierto solapamiento temporal que oscurece la secuencialidad:

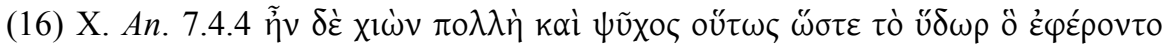

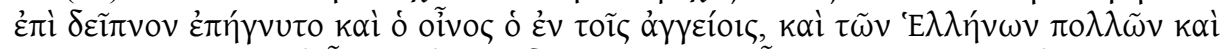

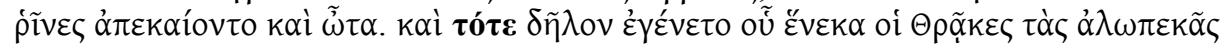

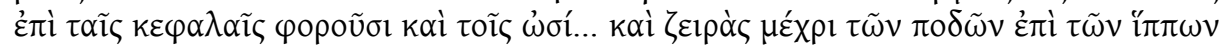

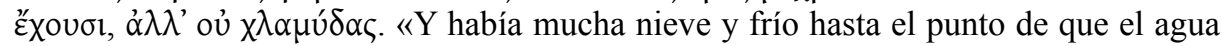
que traían para la cena se congelaba así como el vino de las vasijas, y a muchos de los griegos se les quemaron la nariz y las orejas. Y entonces se hizo evidente por qué los tracios llevan pieles de zorro en la cabeza y las orejas y tienen para ir a caballo capas hasta los pies en lugar de clámides.» 
El hecho de que los griegos comprendieran por qué los tracios visten pieles de animales es consecuencia de haber sufrido los rigores del invierno en su territorio. Por lo demás, el inicio de ese estado de conocimiento coincide temporalmente con la situación en la que los griegos sufren el invierno tracio. De forma que $\tau o ́ \tau \varepsilon$ articula la relación temporal que existe entre los dos eventos, pero también el proceso deductivo en virtud del cual la compresión del uso de determinada ropa de invierno por parte de los tracios se produce a partir de la propia experiencia de su invierno.

— Con sentido temporal ع́v $\theta \alpha$ tiene una semántica parecida a la de $\tau o ́ \tau \varepsilon$, se trata de un adverbio derivado del tema pronominal $* h$ en- con un sufijo locativo $-\theta \alpha$, que se emplea con sentido temporal tan frecuentemente como local. El léxico de Sturz (1964) hace referencia a su sentido consecutivo en ciertos pasaje ${ }^{26} \mathrm{y}$ con valor consecutivo solo he encontrado ejemplos en Jenofonte, a excepción de otro en Heródoto ${ }^{27}$. El adverbio aparece siempre en primera posición con la partícula $\delta \eta ́$, salvo en X. An . 7.2.16 y $\mathrm{Mem}$. 1.2.38. Introduce el último miembro de una unidad narrativa que resulta ser el efecto de lo narrado:

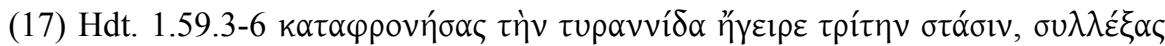

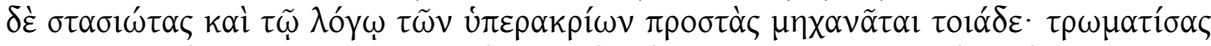

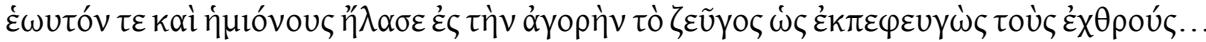

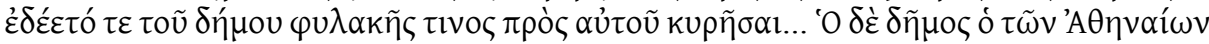

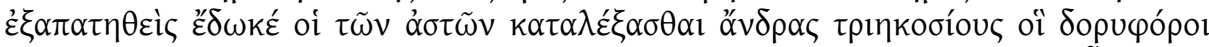

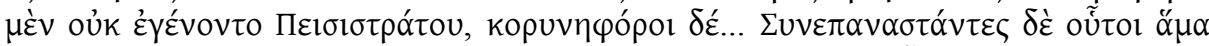

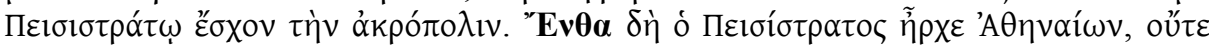

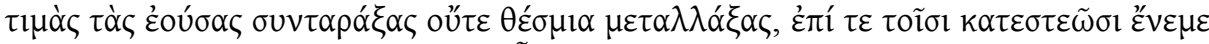

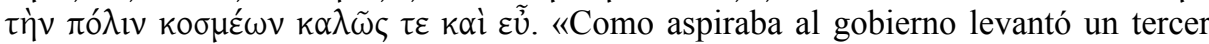
partido, reuniendo partidarios y poniéndose al frente de la causa de los montañeses con el siguiente plan: tras herirse a sí mismo y a sus mulas condujo el carro hasta el ágora como si huyera de sus enemigos... Pidió al pueblo obtener de su parte una guardia personal... y el pueblo de los atenienses, engañado, le concedió elegir a trescientos ciudadanos que se convirtieron no en lanceros de Pisístrato, sino en sus portadores de mazas... Estos se levantaron en armas con Pisístrato y se hicieron con la Acrópolis. Entonces Pisístrato fue el gobernante de los atenienses sin alterar las magistraturas existentes ni cambiar sus leyes y administró la ciudad sobre esos principios gestionándolo todo de forma conveniente.»

En la oración introducida por $\tilde{\varepsilon} v \theta \alpha$, la última del episodio, el verbo es un imperfecto $(\tilde{\hat{\eta}} \rho \chi \varepsilon)$ frente al aoristo de la oración anterior (ž́Xov). El efecto de la toma del poder de Pisístrato en Atenas es, precisamente, el estado subsecuente, en virtud del cual Pisístrato era el tirano de Atenas. La interpretación de ع̌v $\theta \alpha$ como adverbio delimitativo (Schrader en Gredos: «Desde entonces, y como es natural, Pisístrato se hizo el amo de Atenas», Balasch en Cátedra: «Desde entonces Pisítrato fue el dueño de

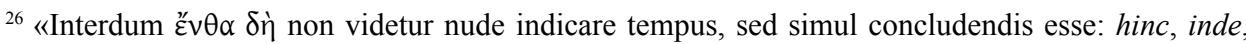
itaque» (s. u. 6).

${ }^{27}$ Cf. Hdt. 1.59.6, X. An. 3.3.4, 4.5.6, 7.2.16, Cyr. 1.4.25, HG 7.2.9, Lac. 3.4, Mem. 1.2.38.
} 
Atenas», Legrand en LBL: «Pisistrate, dès lors, régna sur les Athéniens») no se ajusta a su semántica de tipo locativo.

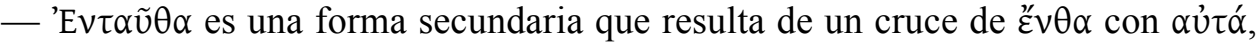
lo que constituye una innovación del griego (DELG y EDG: $s$. u. हैv $\theta \alpha)$. La diferencia más perceptible en su funcionamiento como conectores en nuestro corpus es que $\dot{\varepsilon} v \tau \alpha \tilde{U} \theta \alpha$ suele aparecer con más frecuencia sin ir acompañado de partícula o conjunción. Por otro lado, cuando tiene matiz consecutivo, es frecuente que el miembro discursivo que introduce no sea el último del episodio. Los ejemplos son fundamentalmente de Heródoto y Jenofonte, pero también he encontrado un ejemplo en Tucídides $^{28}$ :

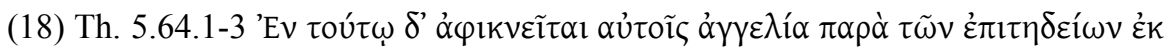

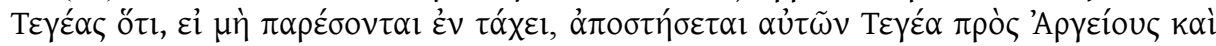

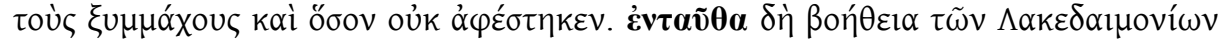

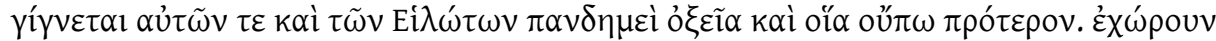

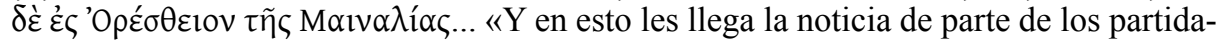
rios de Tegea de que, si no se presentaban rápidamente, Tegea se pasaría de su bando al de los argivos y sus aliados y que casi había hecho defección. Entonces se produce una expedición de ayuda de espartanos e hilotas en masa rápida y grande como nunca antes. Y avanzaron a Oresteo de Menalia...»

De nuevo el adverbio se emplea en una secuencia narrativa introduciendo el efecto de lo anterior, ocupa primera posición de frase y se construye con conjunciones y partículas, si bien también hay bastantes ejemplos en que conecta por sí solo ${ }^{29}$.

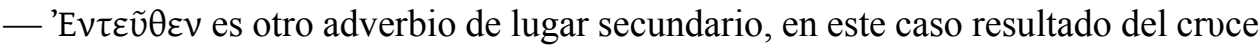
de $\tilde{\varepsilon} v \theta \varepsilon v$ con $\alpha u ̉ \tau o ́$, que se suele usar con un sentido temporal similar al de $\dot{\varepsilon} v \tau \alpha \tilde{u} \theta \alpha^{30}$. Se trata de un adverbio que etimológicamente denota origen (sufijo $-\theta \varepsilon v$ ), siendo la proyección metafórica del origen a la causa frecuente en griego y en otras lenguas (Nikiforidou 1991: 175-176). No obstante, los ejemplos en que se usa con matiz consecutivo son escasos y muy similares a los de $\dot{\varepsilon} v \tau \alpha \tilde{v} \theta \alpha^{31}$.

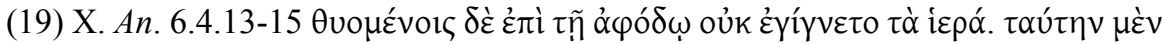

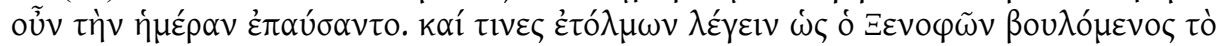

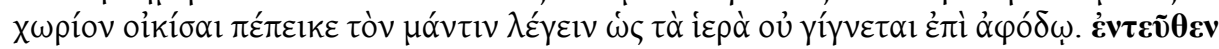

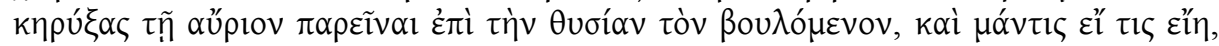

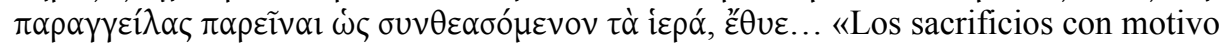

${ }^{28}$ Cf. Hdt. 1.79.2, 1.190.2, 2.151.2, 3.147.2, 3.154.2, 4.200.2, 5.14.1, 5.120.1, 6.126.3, 6.138.4, 7.1.3, 8.126.3, Th. 5.64.2, X. An. 3.4.20, 3.4.41, 3.5.13, 4.3.7, 5.6.36, 5.8.6, 6.1.13, 7.3.25, Cyr. 1.4.28, 2.2.3, 2.2.5.

${ }^{29}$ Cf. Hdt. 1.79.2, 1.190.2, 2.151.2, 3.147.2, 3.154.2, 5.14.1, 6.126.3, 6.138.4, X. An. 3.4.20, 3.4.41, 3.5.13, 6.1.13.

${ }^{30}$ «Saepe confundi solent $\dot{\varepsilon} v \tau$. et $\dot{\varepsilon} v \tau \varepsilon \tilde{v} \theta \varepsilon v 》(T h G L:$ s. u. $\dot{\varepsilon} v \tau \alpha \tilde{v} \theta \alpha)$.

${ }^{31}$ Cf. Hdt. 8.16.1, X. An. 4.4.10, 5.5.3, 6.4.15, 7.5.6. 
de la salida no eran favorables. Así que pararon ese día, y algunos se atrevían a decir que Jenofonte, porque quería colonizar la zona, tenía convencido al adivino para decir que los sacrificios no eran favorables. Entonces, tras proclamar que al día siguiente podía asistir al sacrificio el que quisiera y que si alguno era adivino estaba obligado a asistir para inspeccionar las víctimas, hizo el sacrificio...»

En este caso, el adverbio conecta por sí solo, esto es, funciona como un conector de pleno derecho. Por otro lado, la sucesión temporal es evidente, pero también la relación de causalidad entre los dos miembros conectados: a Jenofonte lo acusan de amañar los oráculos y entonces proclama que el próximo oráculo lo tomará en presencia de todos. El sentido de $\varepsilon \vee v \tau \varepsilon \tilde{U} \theta \varepsilon v$ en el ejemplo es más bien temporal que local, y así lo entienden los traductores: «Entonces... ofreció el sacrificio» (Bach Pellicer, Gredos), «Jenofonte, entonces... celebró el sacrificio» (Varias, Cátedra), «Entonces Jenofonte hizo publicar... Hecho esto, sacrificó delante de muchos testigos» (Sánchez Rivero, Espasa-Calpe). Sin embargo, en su matiz consecutivo influye su valor de origen, pues es muy típico en griego entender metafóricamente la causa como el origen del efecto ${ }^{32}$. En este punto hay que señalar que no he encontrado ningún ejemplo en mi corpus con

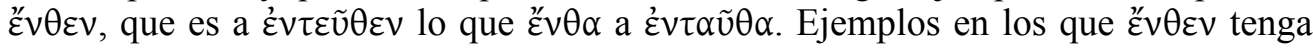
valores discursivos con matiz consecutivo no son imposibles, como parece indicar $L S J$ (s.u. I. 3).

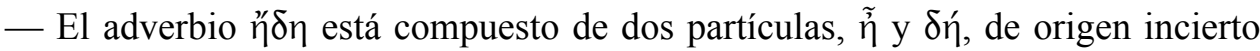
( $G E W, D G E$ y $E D G: s . u$.), y su significado es la suma de los valores afirmativo y confirmativo de esas dos partículas ${ }^{33}$. Se trata de un adverbio con un claro carácter aspectual, lo cual no se compadece demasiado bien con la función de conector ${ }^{34}$, sin embargo, se ha visto un valor consecutivo en algunos ejemplos en los que el adverbio se refiere a una fase temporal anterior que coincide con el evento representado en el miembro discursivo que precede ${ }^{35} \mathrm{y}$ del que la oración que aloja al adverbio se entiende como su efecto. Uno de esos pasajes es el siguiente:

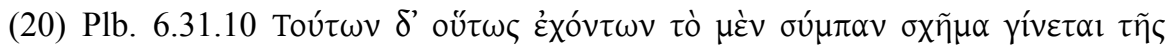

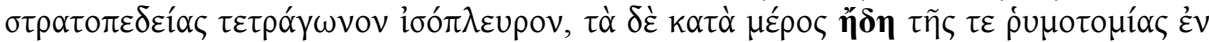

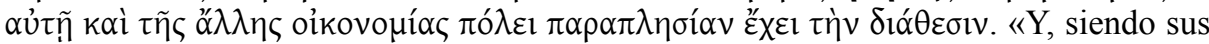

${ }^{32}$ Cf. LSJ (s. u. III.): «causal, thence, from that source...; therefore, in consequence.»

${ }^{33}$ Utilizo la calificación de «confirmativa» de Kühner-Gerth (1904: 123), en lugar de la más extendida e inexacta de «enfática». Con esta partícula el hablante presenta una información como evidente, cf. Smyth (1920: 646), Sicking-Van Ophuijsen (1993: 52).

${ }^{34}$ Van Ophuijsen-Stork (1996: 60) trazan una evolución semántica desde la coalescencia de las dos partículas, $\tilde{\eta}+\delta \eta ́$ subrayando el presente, a una especialización en virtud de la cual el adverbio opone un punto de la línea temporal a lo que le precede («ya») o le sigue («al fin»), indicando que lo que en él ocurre lo hace antes o después de lo esperado. Crespo et alii (2006: 212) lo califican de adverbio de fase y según ellos hace referencia a una fase en la que se da una situación presuponiendo otra anterior o posterior en la que se daba la situación contraria. Su significado varía según el tema aspectual con el que se combina, cf. Jecht (1881).

35 «[...] accidere» (Jecht 1881: 31). 
características así, el esquema completo del campamento llega a ser cuadrangular y ya las distintas calles que hay en él y demás partes tienen una disposición semejante a la de una ciudad.»

El ejemplo viene identificado como consecutivo por Mauersberger et alii ${ }^{36}$. Este fragmento cierra la descripción de la disposición del campamento romano. Polibio hace la descripción siguiendo las distintas partes que se van levantando cuando las legiones acampan. De ahí que se pueda hacer una lectura temporal de $\eta^{\delta} \eta \eta$, si bien con referencia al tiempo del discurso ${ }^{37}$, pues se trata de una descripción abstracta que no está referida a ningún marco temporal concreto.

El grueso de los ejemplos de $\dddot{\delta} \delta \eta$ a los que se atribuye un matiz consecutivo se concentra en Heródoto. A ellos se añaden otros dos posibles ejemplos en Polibio y

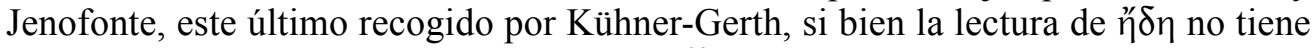
el apoyo unánime de la tradición manuscrita ${ }^{38}$. Lo llamativo de estos ejemplos es que el adverbio se construye con la partícula inferencial oũv (en jonio $\tilde{\tilde{u} v}$ ), además de

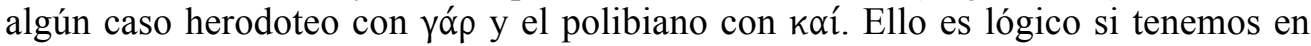
cuenta que su capacidad anafórica es muy limitada y está subordinada a su naturaleza aspectual:

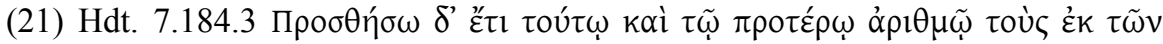

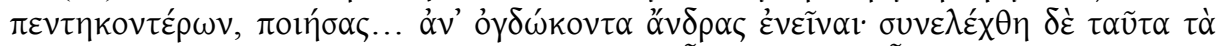

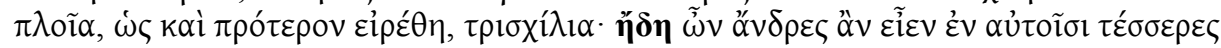
$\mu$ teras, calculando que en cada una de ellas iban ochenta hombres. De estas se reunieron, como se ha dicho antes, tres mil naves. Así pues ya habría en ellas unos veinticuatro mil hombres.»

Los ejemplos en los que se puede ver un matiz consecutivo se caracterizan, en primer lugar, porque se organizan cronológicamente con referencia al tiempo discursivo. En (21) el adverbio introduce el resultado de un algoritmo: Heródoto calcula el número de hombres de la flota asiática de Jerjes que participaron en la batalla de Artemisio a partir del número de naves aportadas por cada contingente. El resultado de los distintos pasos en que se organiza el cálculo se expresa en una oración con un optativo potencial introducida por $\eta \not \delta \eta$. Por otro lado, es característico de estos ejemplos que el adverbio solo no baste para conectar, sino que acompañe a la partícula $\tilde{\omega} v$, que es el verdadero nexo que establece el carácter inferencial de la relación. Con todo, el adverbio refuerza a la partícula insistiendo en que el miembro que introduce es resultado de lo anterior. En este sentido, el matiz discursivo más llamativo de ň $\delta \eta$ suele ser el de añadir cierto relieve a la oración en la que se construye. Este hecho,

\footnotetext{
${ }^{36}$ S. u. III.: gedanklich nunmehr, alsdann, entsprechend.

${ }^{37}$ «Discourse time refers to temporal relationships between utterances in a discourse, i. e. the order in which a speaker presents utterances in a discourse" (Schiffrin: 229).

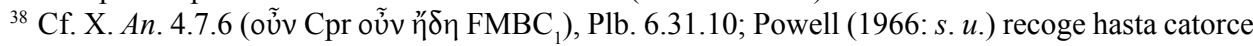
pasajes en los que ve un significado que califica de «lógico», de los que los más claros, en mi opinión, son Hdt. 2.15.2, 2.49.1, 4.86.2, 6.53.2, 7.184.3.
} 
resaltado por Classen ( $a d$ Th. 1.49.7: «den Moment hervorhebend») en el caso del griego, coincide con valores muy similares de adverbios de igual semántica en otras lenguas, caso de esp. ya (Delbecque-Maldonado 2009) y lat. iam (Kroon-Risselada $1998)^{39}$.

- Por último, hay un pasaje en el que se puede hacer una lectura consecutiva de la locución $\mu \varepsilon \tau \alpha \grave{~} \delta \varepsilon ́$. El empleo adverbial de $\mu \varepsilon \tau \alpha ́$ es frecuente en Heródoto para enlazar eventos que se suceden temporalmente en la narración (Powell 1966: s. u. B). En todos los casos se trata de la locución $\mu \varepsilon \tau$ à $\delta \varepsilon$, pues la preposición no tiene capacidad de conectar por sí sola y lo más probable es que se trate de una expresión abreviada de un sintagma del tipo de $\mu \varepsilon \tau \grave{\alpha} \tau \alpha \tilde{v} \tau \alpha^{40}$, donde el pronombre anafórico se refiere a lo anterior. El ejemplo en cuestión es el siguiente:

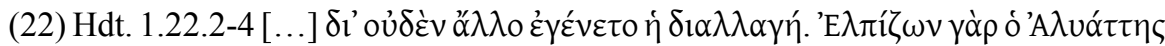

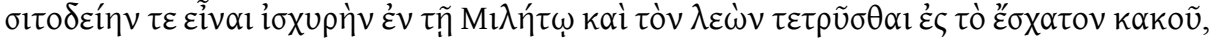

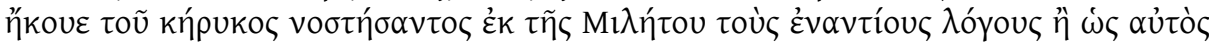

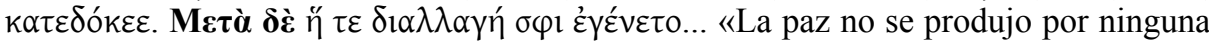
otra causa, pues Aliates, que esperaba que hubiera una terrible escasez en Mileto y que el pueblo estuviera consumido hasta la extenuación, escuchó del heraldo a su vuelta de Mileto noticias contrarias a lo que él pensaba. Y después se produjo la paz entre ellos...»

Si consultamos las traducciones, veremos que estas vacilan entre el valor consecutivo y la sucesión inmediata: «Ensuite de quoi la paix fut rétablie entre les deux parties» (Legrand, LBL), «so presently the Lydians and Milesians ended the war and agreed to be friends and allies» (Godley, Loeb), «Inmediatamente ambos pueblos acordaron

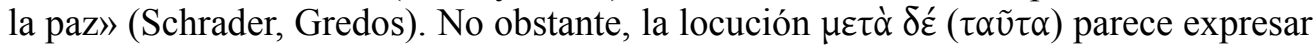
más bien posterioridad: «después (de esto)». Sea como fuere, traducir $\mu \varepsilon \tau \grave{\alpha} \delta \varepsilon ́$ con un sentido consecutivo es subrayar que el evento que introduce es resultado del anterior, por un lado, el fiasco del asedio de Aliates, que aparentemente no ha hecho mella en los milesios, por otro, la paz que este firma una vez fracasado el asedio. Por lo demás, la secuencialidad temporal de los dos eventos es evidente ${ }^{41}$.

${ }^{39}$ Véase la definición del significado del adverbio que da Jecht (1881: 15): «Mea opinione p̆. indicat tempus, in quod actio incidit, referri ad aliud tempus aut sequens aut antecedens et id quidem ita, ut cum vi aliqua significetur eam fieri eo temporis puncto, quod remotius est ab hoc aut futuro aut praegresso tempore» [la negrita es mía].

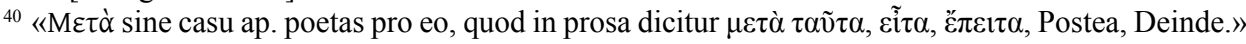
(ThGL: 839).

${ }^{41}$ El pasaje es un tanto más complejo y la expresión $\mu \varepsilon \tau \alpha \grave{~} \delta \varepsilon ́$ introduce la conclusión no solo de la guerra, sino también de la enfermedad de Aliates como consecuencia del incendio del templo de Atenea en Aseso durante las operaciones bélicas. Gracias a la paz, Aliates construyó dos templos dedicados a la diosa y, así, se recuperó (Hdt. 1.19.1-1.22.4). 


\section{DE LO TEMPORAL A LO CONSECUTIVO}

Los adverbios temporales que se documentan funcionando como conectores con valor consecutivo se caracterizan por tener capacidad de hacer referencia al segmento

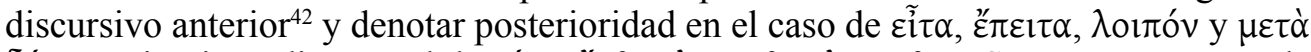

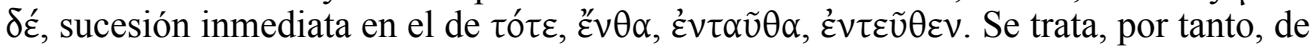
adverbios que pueden expresar secuencialidad, esto es, la organización de los eventos que conforman el texto en una secuencia en primera instancia cronológica sin hacer referencia a un segmento temporal concreto ${ }^{43}$. En este sentido, el empleo de adverbios temporales para conectar los dos miembros de una relación consecutiva es una proyección de la secuencia temporal a la secuencia causal, en virtud de la selección de la temporalidad propia de esta, pues el cumplimiento de la causa suele ser anterior al del efecto.

Por otro lado, desde un punto de vista sintáctico, es característico de estos adverbios el ocupar, cuando funcionan como conectores, la primera posición de su oración ${ }^{44}$. Se trata de una posición temática, desde la que el adverbio tiene alcance sobre toda la oración y, como consecuencia, tiende a segregarse de esta para funcionar como un elemento delimitador entre su oración y la anterior (Martínez en prensa, Gutiérrez

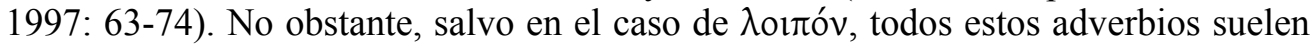
reforzar, en su función de conectores, a conjunciones coordinantes ( $\kappa \alpha i ́, \delta \varepsilon ́$ ) o verse reforzados, a su vez, por partículas conectoras $(\delta \eta)^{45}$. Este hecho está muy relacionado con la costumbre griega de enlazar sintácticamente las oraciones mediante esos elementos (Denniston 1970: 99), de forma que podemos entender que los adverbios refuerzan esa conexión especificando su sentido semántico y pragmático.

Desde un punto de vista semántico, el que se emplee un adverbio de tiempo para articular la relación de causalidad entre dos miembros independientes, en principio, no tiene nada que ver con la explicitación de la consecuencia, sino con el de la secuencia temporal en que se ordenan. Así, muchos de los ejemplos que he encontrado son fronterizos en el sentido de que el adverbio no solo articula la relación consecutiva, sino que explicita la secuencia temporal de esta. Es el caso, fundamentalmente, de los

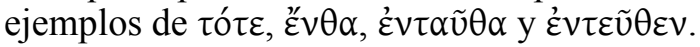

Podemos reconstruir, así, con datos del griego antiguo una parte importante de la evolución típica de los adverbios temporales a conectores consecutivos. El primer paso de esa evolución se produce cuando el adverbio deja de emplearse como modificador del verbo para pasar a un nivel sintáctico superior en el que conecta unidades

${ }^{42}$ Véase Portolés (2000) para la evolución de unidades deícticas a marcadores discursivos cuando señalan a un miembro discursivo anterior a aquel que las incluye (deixis discursiva).

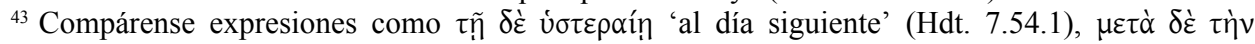
$v \alpha u \mu \alpha \chi i ́ \alpha v$ 'después de la batalla naval' (Th. 1.30.1), $\mu \varepsilon \tau$ ' ỏ $\lambda$ ípov $\delta \varepsilon \dot{\varepsilon} \tau o u ́ \tau \omega v$ 'poco después de esto'

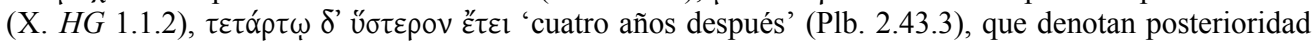
con respecto al evento anterior, pero haciendo referencia a un segmento temporal específico. Esta especificidad bloquea otras interpretaciones que no sean temporales.

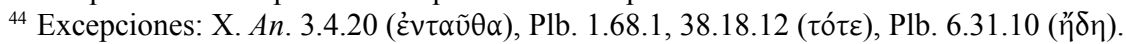

${ }^{45} \Delta \eta$ funciona como partícula conectora a partir del s. IV a. C., pero ya con anterioridad se observa su empleo en contextos que darán origen a esa función, cf. Denniston 1954: 236-238. 
discursivas que se ordenan desde un punto de vista cronológico. Si entre esas unidades hay una relación de tipo consecutivo, el adverbio no pierde su sentido temporal, pero el hablante puede inferir que ese valor temporal es parte de la secuencialidad causal. Es lo que Traugott-Dasher (2002) denominan «cambio semántico por inferencia invitada», el hablante dota al adverbio de significados no referenciales que dependen de su contexto discursivo, los convencionaliza y puede terminar reanalizándolos como parte del significado polisémico del adverbio. En este sentido, el empleo de عĩ $\tau \alpha$ y para introducir interrogaciones enfáticas está bastante convencionalizado en griego

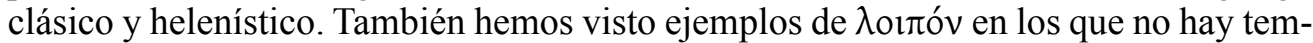
poralidad, de forma que la lectura temporal del adverbio se bloquea y la interpretación consecutiva pasa a un primer plano. Estos ejemplos son llamativos porque anuncian el empleo del adverbio como conjunción ilativa en griego moderno.

\section{A MODO DE CONCLUSIÓN}

En griego los adverbios y locuciones adverbiales temporales que expresan secuencialidad desarrollan sentidos consecutivos cuando conectan dos miembros discursivos de los que el segundo se puede entender como una consecuencia del anterior. Se trata de una proyección de la secuencia temporal a la consecutiva y este empleo es claramente subsidiario del uso de estos adverbios como conectores puramente temporales.

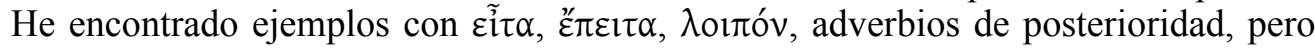

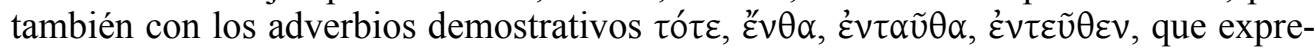
san sucesión inmediata, e incluso un posible ejemplo con la locución conjuntiva $\mu \varepsilon \tau \grave{̀}$ $\delta \varepsilon ́$. En cuanto a $\eta \not \delta \eta$ su uso como conector es mucho menos evidente que en el resto de casos dado que su significado es de carácter aspectual.

\section{BiBLIOGRAFÍA}

Bach Pellicer, Ramón (1982), Jenofonte. Anábasis. Madrid.

BAlasch Recort, Manuel (1999), Heródoto. Historia. Madrid.

BÉTANT, Éli Ami $\left(1969^{2}\right)$, Lexicon Thucydideum. Hildesheim.

BLOMQVist, Jerker (1969), Greek particles in Hellenistic prose. Lund.

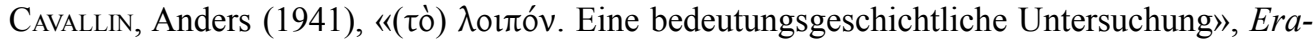
nos 39: 121-144.

Classen, Johannes (1862-1878), Thukydides. Berlin.

CONTI JiMÉNEZ, Luz (en prensa), «Zu Konjunktionaladverbien im Altgriechischen: Analyse von ह̈лєı $\alpha$ bei Homer», en Von Fall zu Fall. Beiträge zur indogermanischen Kasussyntax.

CRESPO GÜEMES, Emilio (2011), «Conjunctive adverbs: a neglected chapter to Greek grammar», en E. R. Luján y J. L. García Alonso (eds.), A Greek Man in the Iberian Street. Studies in Linguistics and Epigraphy in honour of Javier de Hoz, Innsbruck: 35-44.

Crespo Güemes, Emilio, Conti Jiménez, Luz, Maquiera Rodríguez, Helena (2003), Sintaxis del griego clásico. Madrid. 
Delbecque, Nicole - Maldonado, Ricardo (2009), «Ya. Ancla conceptual de una progresión programática», en L. Puig (ed.), El discurso y sus espejos, México: 189-235.

DELG = Chantraine, Pierre (1968-1980), Dictionnaire étymologique de la langue grecque. Paris.

Denniston, John D. (1954²), The Greek particles. Oxford.

Denniston, John D. (1970), Greek prose style. Oxford.

DGE = Rodríguez Adrados, Francisco (1980-), Diccionario griego-español. Madrid.

Domínguez García, María Noemí (2010), «Los marcadores del discurso y los tipos textuales», en O. Loureda y E. Acín (eds.), Los estudios sobre marcadores del discurso en español, hoy, Barcelona: 359-413.

Dover, Kenneth J. (1997), The evolution of Greek prose style. Oxford.

$E D G=$ BEEKES, Robert S. P., VAN BEEK, Lucien (2010), Etymological dictionary of Greek. Leiden.

Fraser, Bruce (2006), «Towards a theory of discourse markers», en K. Fischer (ed.), Approaches to discourse particles, Amsterdam: 189-204.

GEW = FRISK, Hjalmar (1960-1972), Griechisches etymologisches Wörterbuch. Heidelberg. Godley, Alfred D. (1920-1925), Herodotus. Cambridge.

Fuentes Rodríguez, Catalina (2009), Diccionario de conectores y operadores del español, Madrid.

GARCía FernÁndez, Luis (1999), «Los complementos adverbiales temporales. La subordinación temporal», en I. Bosque y V. Demonte (eds.), Gramática descriptiva de la lengua española, Madrid: 3129-3208.

Gili GayA, Samuel (1943), Curso superior de sintaxis española. México.

GutiérRez OrdóÑEz, Salvador (1997), Temas, remas, focos, tópicos y comentarios. Madrid.

Hallyday, Michael A. K., Hasan, Ruqaiya (1976), Cohesion in English. London.

HiLton, John (1999), «The role of discourse and lexical meaning in the gramaticalización of temporal particles in Latin», Glotta 74: 198-210.

JECHT, Richard (1881), De usu particulae $\ddot{\delta} \eta$ in Platonis dialogis qui feruntur. Halle.

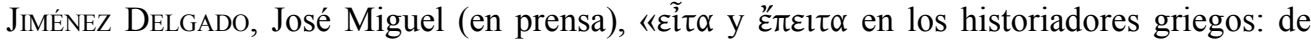
adverbios temporales a marcadores discursivos », XIII Congreso Español de Estudios Clásicos, Logroño, 2011.

KöNIG, Ekkehard, TraugotT, Elisabeth C. (1988), «Pragmatic strengthening and semantic change: the conventionalizing of conversational implicature», en W. Hüllen y R. Schulze (eds.), Understanding the Lexicon: Meaning, sense and world knowledge in lexical semantics, Tübingen: 110-124.

Kroon, Caroline, Risselada, Rodie (1998), «The discourse functions of iam», en E. Nieto, R. López, B. García y M. E. Torrego (coords.), Estudios de lingüística latina: actas del IX Coloquio Internacional de Lingüistica Latina, Madrid: 429-445.

KÜHNER, Raphael, GERTH, Bernhard (1904³), Ausführliche Grammatik der griechischen Sprache. Zweiter Teil: Satzlehre. II. Band. Hannover-Leipzig.

Legrand, Phillip-Ernest (1932-1954), Hérodote. Histoires. Paris.

Llamas Saíz, Carmen (2010), «Los marcadores del discurso y su sintaxis», en O. Loureda y E. Acín (eds.), Los estudios sobre marcadores del discurso en español, hoy, Madrid: 183-239.

LoudovÁ, Kateřina (2009), «Discourse markers in early Bizantine narrative prose», Studies in Greek Linguistics 29: 296-312. 
$L S J=$ Liddell, Henry G., Scott, Robert, Jones, Henry S. $\left(1940^{9}\right)$, A Greek-English lexicon . Oxford.

Maquieira, Helena (2012), «Los usos conjuntivos de ع̌ comunicación presentada al XLI Simposio de la SEL.

Martín Zorraquino, María Antonia, Portolés LÁzAro, José (1999), «Los marcadores del discurso», en I. Bosque y V. Demonte (eds.), Gramática descriptiva de la lengua española, Madrid: 4051-4213.

Martínez VÁzquez, Rafael, Ruiz Yamuza, Emilia (2011), «Una aproximación escalar al empleo del adverbio como adjunto y conjunto: oṽ $\omega \varsigma »$, Habis 42: 317-337.

Martínez VÁzquez, Rafael (2011), «Tipología textual, adverbios conjuntivos y la Historia de Tucídides», en R. Carande y D. López-Cañete (eds.), Pro tantis redditur. Homenaje a Juan Gil en Sevilla, Zaragoza: 81-97.

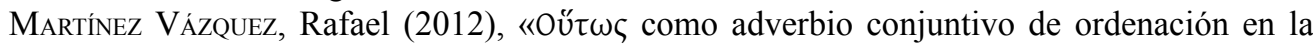
lengua de Tucídides», en A. Cabedo, P. Nebot (eds.), Lingüística XL. El lingüista del siglo XXI, Madrid: pp. 141-147.

MARTínEZ VÁzQUEZ, Rafael (en prensa), «The theory of discourse markers and conjunctive adverbs in Ancient Greek. The role of informative structure in defining the conjunctive function», en International Conference on Linguistics and Classical Languages, Roma, 2011.

Mauersberger, Arno, Collatz, Christian-Friedrich, Helms, Hadwig, SchäFer, Melsene (2000$\left.2006^{2}\right)$, Polybios-Lexikon. Berlin.

Mirambel, André $\left(2002^{2}\right)$, Grammaire du grec moderne. Paris.

Nikiforidou, K. (1991), «The meaning of the genitive: a case study in semantic structure and semantic change», Cognitive Linguistics 2/2: 149-205.

Pons Bordería, Salvador (1998), Conexión y conectores. Estudio de su relación en el registro informal de la lengua. Valencia.

Portolés LÁzAro, José (2000), «El origen de los marcadores y la deixis discursiva», en P. Carbonero, M. Casado y P. Gómez (eds.), Lengua y discurso. Estudios dedicados al profesor Vidal Lamíquiz, Madrid: 773-782.

Powell, John E. (1966), A lexicon to Herodotus. Hildesheim.

Quirk, Randolph, Greenbaum, Sidney, Leech, Geoffrey, Svartvik, Jan (1985), A comprehensive grammar of the English language. New York.

Rehdantz, Carl - Blass, Friedrich $\left(1986^{4}\right)$, Demosthenes ausgewählte Reden. Erster Teil: die neun philippische Reden. Zweites Heft. II. Abteilung. Leipzig.

Romera Ciria, Magdalena (2003), «Un análisis semántico del adverbio temporal entonces», Linred: Revista electrónica de lingüística 1: 1-26.

Ruiz Yamuza, Emilia (en prensa), «Apodotic uses between syntax and text», en International Conference on Linguistics and Classical Languages, Roma, 2011.

SÁnChEZ Rivero, Ángel (1930), Jenofonte. La expedición de los diez mil (Anábasis). Madrid.

Schiffrin, Deborah (1987), Discourse markers. New York.

Schrader García, Carlos (1977-1989), Heródoto. Historia. Madrid.

Sicking, Christiaan M. J., Van Ophuissen, Johannes M. (1993), Two studies in Attic particle usage: Lysias and Plato. Leiden.

Sмyтн, Herbert W. $\left(1920^{2}\right)$, A Greek grammar for the colleges. New York.

STURz, Friedrich W. (1964'), Lexicon Xenophonteum. Hildesheim.

$T h G L=$ Stephanus, Henricus (1954), Thesaurus Graecae Linguae. Graz. 
Traugott, Elisabeth C., Dasher, Richard B. (2002), Regularity in semantic change. New York. Triantaphyllidis, Manolis (2002), Lexiko tes koines Neoellenikes. Thessaloníki.

VAn Ophuijsen, Johannes M., Stork, Peter (1999), Linguistics into interpretation: speeches of war in Herodotus VII 5 \& 8-18. Leiden.

VARIAs García, Carlos (1999), Jenofonte. Anábasis. Madrid. 